\title{
The Metabolism of Sialic Acid in Cystic Fibrosis
}

\author{
YÓAV BEN-YOSEPH, ${ }^{(26)}$ C. L. DEFRANCO, AND HENRY L. NADLER \\ Department of Pediatrics, Northwestern University Medical School, Division of Genetics, Children's Memorial \\ Hospital, Chicago, Illinois, USA
}

\begin{abstract}
Summary
The activities of plasma and fibroblast cytidine $5^{\prime}$-monophosphate-sialic acid:glycoprotein sialyltransferases of patients with cystic fibrosis have been found to be within the range of activities of age- and sex-matched normal controls when asialofetuin served as the sialic acid acceptor. The use of desialylated preparations of purified human plasma $\alpha_{2}$-macroglobulin, as an acceptor, demonstrated 35 to $52 \%$ reduction in the incorporation of sialic acid into the $\alpha_{2}$-macroglobulin from patients with cystic fibrosis as compared to that of $\alpha_{2}$-macroglobulin from normal controls. The reduced sialylation was dependent upon the source of the $\alpha_{2}$ macroglobulin acceptor but independent of the source (cystic fibrosis or normal) of the sialyltransferase enzyme. Using radiolabeled precursors, the rates of the synthesis of $\mathrm{N}$-acetylneuraminic acid from $\mathrm{N}$-acetyl-D-mannosamine, the release of sialic acid from glycoproteins and the conversion of free sialic acid into CMP-sialic acid have been determined in cultured skin fibroblasts from patients with cystic fibrosis and found to be not significantly different from those of normal controls.
\end{abstract}

\section{Speculation}

The reduced sialylation of desialylated preparations of purified $\alpha_{2}$-macroglobulin from patients with cystic fibrosis as compared to that of asialo- $\alpha_{2}$-macroglobulin from age- and sex-matched normal controls indicates a possible alteration in the carbohydrate moiety of glycoproteins in cystic fibrosis. The metabolism of sialic acid appears, however, to be normal in this disease and could not account for the observed differences. Additional glycoproteins and glycosyltransferases should be examined to find out if a general defect in glycosylation is involved in cystic fibrosis.

Cystic fibrosis (CF) is an autosomal recessive disorder, one of the most common genetic diseases among Caucasian populations (13). The disease involves abnormality of all exocrine glands, associated with highly viscous mucus secretions (9). The major manifestations are pancreatic exocrine deficiency, chronic pulmonary disease, and abnormally high sodium and chloride concentrations in sweat (13). The disease is lethal, and death usually occurs before or in early adulthood. Numerous biochemical abnormalities were reported in patients with $\mathrm{CF}$ but the basic biochemical defect has not been as yet elucidated.

Many studies have found altered glycoproteins in CF patients (1) and these abnormal glycoproteins are thought to contribute to the pulmonary and gastrointestinal pathology of the disease. Carbohydrate analyses of duodenal fluid (10), sweat (14), and rectal mucus (16) fractions from patients with CF have shown an increased ratio of $\mathrm{L}$-fucose to sialic acid as compared to normal controls. Altered carbohydrate composition was also reported in the glycoprotein $\alpha$-L-fucosidase, purified to homogeneity from liver of CF patients (2). The amounts of D-mannose, $N$-acetyl-Dglucosamine, and sialic acid were reduced to 30 to $50 \%$ of their content in normal liver $\alpha$-L-fucosidase. Comparative studies on the enzymes involved in the metabolism of the carbohydrate moiety of glycoproteins in CF patients and normal controls have been reported for several glycosidases and glycosyltransferases ( 1 , 13). Although altered levels of activity were found for some of the enzymes studies, the results were inconsistent in the case of lysosomal hydrolases and highly dependent on the source of the enzyme and the type of the acceptor substrate in the case of glycosyltransferases

Previous studies in our laboratory have documented that an altered $\alpha_{2}$-macroglobulin $\left(\alpha_{2} \mathbf{M}\right)$ is present in CF plasma. The $\alpha_{2} \mathrm{M}$ from patients with CF demonstrated an abnormal interaction with various proteolytic enzymes (17) but was indistinguishable from normal $\alpha_{2} \mathrm{M}$ by its antigenicity and ultraviolet absorbance spectra (18). Two-dimensional electrophoretic analysis of purified $\alpha_{2} \mathrm{M}$ preparations from CF and normal did not reveal any significant differences between the two species (8). However, the content of sialic acid was found to be reduced in the CF $\alpha_{2} \mathrm{M}$ and its binding to the lectins concanavalin $\mathrm{A}$ and wheat germ agglutinin was lower than that of the normal (5).

The present study was undertaken to find out if a defect in the metabolism of glycoprotein-sialic acid is involved in cystic fibrosis. The enzymic activities leading to the de novo synthesis of sialic acid, the recycling of sialic acid from glycoconjugates by neuraminidases, the formation of the nucleotide-sugar, cytidine 5'monophosphate (CMP)-sialic acid, and the sialylation process were studied in plasma and cultured skin fibroblasts from CF patients and normal controls.

\section{MATERIALS AND METHODS}

$\left[6-{ }^{3} \mathrm{H}\right]-\mathrm{N}$-Acetyl-D-mannosamine (ManNAc), $31.5 \mathrm{Ci} / \mathrm{mmole}$, $\left[4-{ }^{14} \mathrm{C}\right]-\mathrm{N}$-acetylneuraminic acid (NeuNAc), $49 \mathrm{mCi} / \mathrm{mmole}$, and cytidine monophosphate- $\left[9-{ }^{3} \mathrm{H}\right]-\mathrm{N}$-acetylneuraminic acid (CMPNeuNAc), $18.9 \mathrm{Ci} / \mathrm{mmole}$ were from New England Nuclear (Boston, MA). Adenosine 5'-triphosphate (ATP), cytidine 5'-triphosphate (CTP), nicotinamide adenine dinucleotide, nicotinamide adenine dinucleotide phosphate, phenylmethyl sulfonylfluoride, agarose-bound neuraminidase (Clostridium perfringens), soybean trypsin inhibitor (type 1-S), and phosphoenol pyruvic acid (PEP) were from Sigma Chemical (St. Louis, MO). ManNAc, NeuNAc, neuramine lactose (beef colostrum), and fetuin (fetal calf serum) were from Calbiochem-Behring (LaJolla, CA).

Skin fibroblasts were obtained by punch biopsies from three patients with CF and three normal controls. All were males 13 to 14 years of age. The cells at their third to fifth passage were cultured and harvested as previously described (4). Fibroblast lysates were prepared in five volumes of distilled water by five consecutive cycles of freezing and thawing. Whole homogenates were used for enzyme assays, and boiled cell lysates served as blanks. Plasma was separated from fresh venous blood obtained from three patients with $\mathrm{CF}$ and three normal controls. All were 12- to 14-year-old males. Blood was collected on $3.8 \mathrm{mg} / \mathrm{ml}$ sodium citrate, and the protease inhibitors phenylmethyl sulfonylfluoride and soybean trypsin inhibitor were added at final concentrations of 0.1 and $0.16 \mathrm{mg} / \mathrm{ml}$, respectively. Protein was determined by the dye binding assay (6) using bovine $\gamma$-globulin as a standard. Absorbance measurements were made on a Beckman D.B. spectrophotometer, and radioactivity of ${ }^{3} \mathrm{H}$ and ${ }^{14} \mathrm{C}$ was monitored by a Tricarb scintillation spectrometer.

Synthesis of sialic acid from $N$-acetyl-D-mannosamine (Fig. 1, reactions 1 to 3 ) was assayed according to Warren and Glick (20) using fibroblast lysate as the source of enzymes. The reaction 


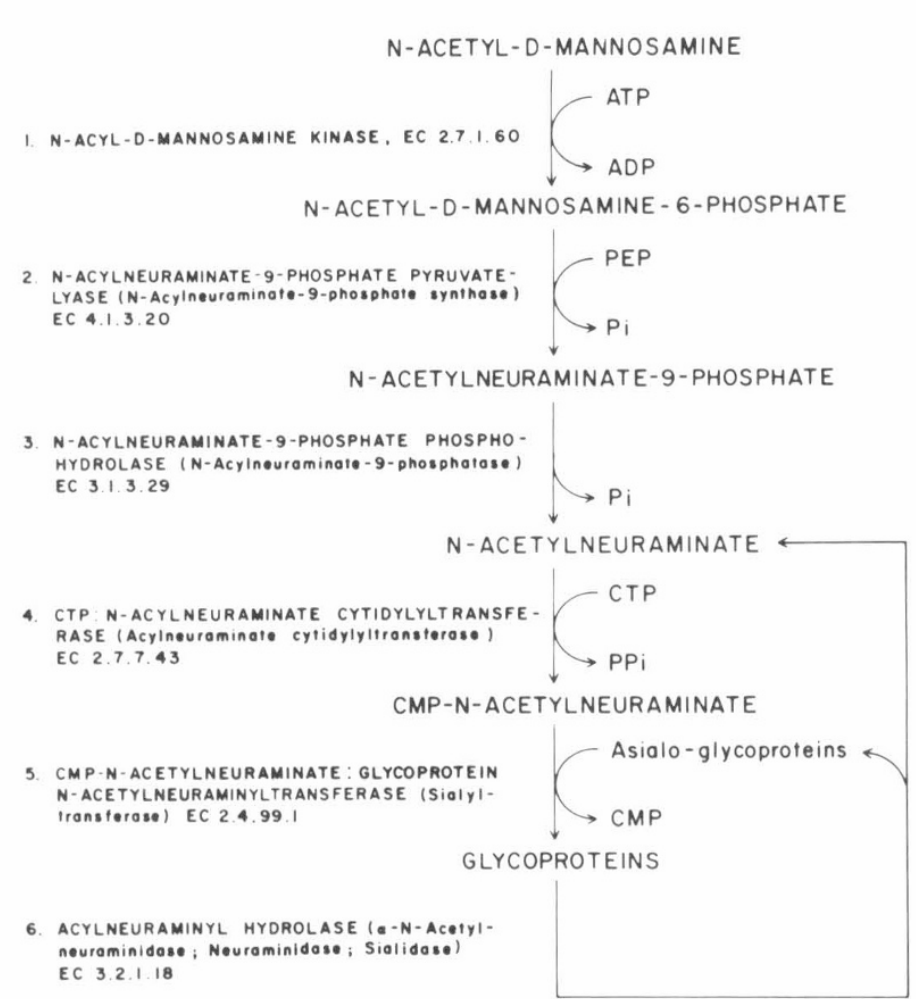

Fig. 1. The metabolism of glycoprotein-sialic acid. Synthesis, reactions 1 to 3 ; activation reaction 4 ; sialylation, reaction 5 ; and desialylation, reaction 6. $A D P$, adenosine 5 -diphosphate; $P_{i}$, inorganic phosphate; $P P_{i}$, inorganic pyrophosphate.

mixture contained $100 \mu \mathrm{g}$ cell protein, 100 nmoles $\left[6-{ }^{3} \mathrm{H}\right] \mathrm{ManNAc}$ (6,800 dpm/nmole), 400 nmoles ATP, 2400 nmoles $\mathrm{MgCl}_{2}, 1600$ nmoles PEP, 20 nmoles nicotinamide adenine dinucleotide and 20 nmoles nicotinamide adenine dinucleotide phosphate in a final volume of $0.2 \mathrm{ml}$ of $0.1 \mathrm{M}$ Tris-acetate buffer, $\mathrm{pH}$ 7.6. After incubation for $3 \mathrm{hr}$ at $37^{\circ} \mathrm{C}$, the sialic acid formed was either quantitated chemically by the thiobarbituric acid assay (3) or radioactively after separation from the radiolabeled precursor by descending paper chromatography (Whatman No. 3, $50 \times 20 \mathrm{~cm}$ ) in $n$-butanol/pyridine/water, $6 / 4 / 3$ (by volume). The relative mobilities ( $R_{f}$ values) were 0.07 and 0.53 for NeuNAc and ManNAc, respectively. The corresponding areas were cut out from the chromatogram and placed in scintillation vials containing 10 $\mathrm{ml}$ Bray's solution (7), and the radioactivity was measured.

The activity of fibroblast CTP: $N$-acylneuraminate cytidyltransferase (EC 2.7.7.43; Fig. 1, reaction 4) was assayed according to Kean and Roseman (12) by incubating $100 \mu \mathrm{g}$ cell lysate 4000 nmoles $\mathrm{MgCl}_{2}, 1000$ nmoles CTP, and 1000 nmoles $\left[4-{ }^{14} \mathrm{C}\right]$ NeuNAc $(10,800 \mathrm{dpm} / \mathrm{nmole})$ for $2 \mathrm{hr}$ at $37^{\circ} \mathrm{C}$ in final volume of $0.2 \mathrm{ml}$ of $0.1 \mathrm{M}$ Tris- $\mathrm{HCl}$ buffer, $\mathrm{pH}$ 8.2. The product, CMPNeuNAc, was isolated from the reaction mixture by descending paper chromatography (Whatman No. 3, $50 \times 20 \mathrm{~cm}$ ) in $0.1 \mathrm{M}$ ammonium acetate buffer, $\mathrm{pH} 7.5$, containing $70 \%$ ethanol. The $\mathrm{R}_{\mathrm{f}}$ values were 0.22 for CMP-NeuNAc and 0.61 for the free sialic acid.

CMP-NeuNAc:glycoprotein $N$-acetylneuraminyltransferase (EC 2.4.99.1; Fig. 1, reaction 5) activity was measured in plasma and fibroblast lysates using desialylated preparations of fetal calf serum fetuin and human plasma $\alpha_{2} \mathrm{M}$ as the glycoprotein acceptors. Purification of $\alpha_{2} \mathrm{M}$ from the three cystic fibrosis and three normal plasma samples was carried out as previously described (5). Greater than $95 \%$ sialic acid (3) was removed by hydrolyzing the glycoprotein $(5 \mathrm{mg} / \mathrm{ml})$ for $1 \mathrm{hr}$ at $80^{\circ} \mathrm{C}$ in $0.1 \mathrm{~N} \mathrm{H}_{2} \mathrm{SO}_{4}$. Neuraminidase treatment was used as an alternative method, and 55 to $65 \%$ of the initial sialic acid (3) was removed by this procedure. Agarose-bound neuraminidase was shaken for $24 \mathrm{hr}$ at $37^{\circ} \mathrm{C}$ with $2.5 \mathrm{mg}$ glycoprotein in $0.5 \mathrm{ml}$ of $0.1 \mathrm{M}$ sodium acetate buffer, pH 5.0. Aliquots containing 0.1 unit enzyme each, were added initially and after 6 and $12 \mathrm{hr}$ incubation. The insoluble neuraminidase was spun down, and sialic acid was discarded from the desialylated preparations by dialysis against $0.1 \mathrm{M}$ Tris- $\mathrm{HCl}$ buffer, $\mathrm{pH} 7.5$. The sialylation mixture contained $50 \mu \mathrm{l}$ plasma or $100 \mu \mathrm{g}$ fibroblast lysate protein, $0.2 \mathrm{mg}$ fetuin or $1 \mathrm{mg} \alpha_{2} \mathrm{M}$, and 150 nmoles CMP- $\left[9-{ }^{3} \mathrm{H}\right]$ NeuNAc $\left(41.8 \times 10^{6} \mathrm{dpm} / \mathrm{nmole}\right)$ in 0.2 $\mathrm{ml}$ of $0.1 \mathrm{M}$ Tris- $\mathrm{HCl}$ buffer, $\mathrm{pH}$ 7.5. The reaction mixture was incubated for $2 \mathrm{hr}$ at $37^{\circ} \mathrm{C}$ and terminated by adding $0.8 \mathrm{ml}$ of $3 \%$ phosphotungstic acid in $0.5 \mathrm{~N} \mathrm{HCl}$. After $16 \mathrm{hr}$ at $4^{\circ} \mathrm{C}$, the glycoprotein precipitate was spun down $(12,000 \times \mathrm{g}$ for $20 \mathrm{~min})$ and washed twice in $1 \mathrm{ml}$ of $2.4 \%$ phosphotungstic acid in $0.4 \mathrm{~N}$ $\mathrm{HCl}$. The washed precipitate was dissolved in $1 \mathrm{ml}$ of $1 \mathrm{~N} \mathrm{NaOH}$ and the radioactivity was measured.

The activity of $\alpha-\mathrm{N}$-acetylneuraminidase (EC 3.2.1.18; Fig. 1, reaction 6) toward neuramine lactose, $\alpha_{2} \mathrm{M}$, and fetuin was assayed using fibroblast lysate prepared by 1 - to $2-\mathrm{sec}$ sonication of freshly harvested cells in five volumes of distilled water. The reaction mixture contained $100 \mu \mathrm{g}$ fibroblast protein and $2000 \mathrm{nmoles}$ neuramine lactose, 1 nmole $\alpha_{2} \mathrm{M}$ or 50 nmoles fetuin in $0.2 \mathrm{ml}$ of $0.1 \mathrm{M}$ sodium acetate buffer, $\mathrm{pH}$ 4.3. The sialic acid released was determined by the thiobarbituric acid assay (3).

\section{RESULTS}

The rate of synthesis of sialic acid from $N$-acetyl-D-mannosamine (Fig. 1, reactions 1 to 3 ) in cultured skin fibroblast of three patients with CF and three age- and sex-matched normal controls is shown in Table 1. The assays were performed in duplicate that agreed within $5 \%$. The production of sialic acid by fibroblasts of the $\mathrm{CF}$ patients was within the range obtained for the normal controls. The direct chemical determination of the sialic acid formed agreed with the determination of its radioactivity after chromatographic separation from the radiolabeled precursor. Omission of ATP or PEP from the reaction mixture resulted in poor synthesis of sialic acid (less than $5 \%$ ) by both the CF and the normal fibroblast lysates. All assays used boiled cell lysates as enzyme blanks.

The activity of CTP:NeuNAc cytidylyltransferase (Fig. 1, reaction 4) in fibroblast lysates from three CF patients $(0.417 \pm$ $0.117 \mathrm{nmoles} / \mathrm{hr} / \mathrm{mg}$ protein) did not differ significantly from that of three normal controls $(0.470 \pm 0.110 \mathrm{nmoles} / \mathrm{hr} / \mathrm{mg}$ protein $)$. Addition of asialofetuin to the reaction mixture (Fig. 1, reaction 5) resulted in a slight decrease in CMP-NeuNAc formed and an increased incorporation of sialic acid into the high-molecularweight fraction which does not migrate in the chomatography system. Figure 2 illustrates similar chromatographic patterns of radioactivity obtained with $\mathrm{CF}$ and normal fibroblast lysates after incubation with CTP, $\left[4-{ }^{14} \mathrm{C}\right] \mathrm{NeuNAc}$, and asialofetuin. Incubation of either type of cell lysate with radiolabeled sialic acid and asialofetuin but no CTP did not show any significant incorporation into the glycoprotein fraction.

Table 1. Synthesis of sialic acid from $N$-acetyl-D-mannosamine and phosphoenol pyruvic acid in cultured skin fibroblasts

$\mathrm{N}$-Acetylneuraminate formed (nmoles/hr/mg protein)

\begin{tabular}{lcc}
\cline { 2 - 3 } Cell line & $\begin{array}{c}\text { Thiobarbiturate } \\
\text { assay }\end{array}$ & $\begin{array}{c}\text { Paper } \\
\text { chromatography }\end{array}$ \\
\hline Normal controls & & \\
1 & 27.3 & 25.0 \\
2 & 28.4 & 26.2 \\
3 & 24.0 & 23.8 \\
CF & & \\
1 & 26.2 & 23.8 \\
2 & 30.6 & 25.6 \\
3 & 35.0 & 28.2 \\
\hline
\end{tabular}


Direct determination of glycoprotein:CMP-NeuNAc sialyltransferase (Fig. 1, reaction 5) activity was carried out in plasma and cultured skin fibroblasts from patients with $\mathrm{CF}$ and normal controls, three of each using CMP- $\left[9-{ }^{3} \mathrm{H}\right] \mathrm{NeuNAc}$ as the sialic acid donor and acid or neuraminidase desialylated preparations of fetal calf serum fetuin or human plasma $\alpha_{2} \mathrm{M}$ as the glycoprotein acceptors. The results obtained for CF and normal plasma and fibroblast samples with and without acid-treated exogenous glycoproteins are summarized in Table 2. Regardless of the enzyme source (CF or normal plasma), similar incorporation of sialic acid into each of the glycoproteins examined (fetuin, $\mathrm{CF}-\alpha_{2} \mathbf{M}$, or normal $\alpha_{2} \mathrm{M}$ ) was determined. In contrast, the sialylation reaction was found to depend upon the source of the glycoprotein acceptor. Acid desialylated preparations of $\alpha_{2} \mathrm{M}$ purified from three $\mathrm{CF}$ plasma samples were poor acceptors for $\mathrm{CF}$ as well as normal sialyltransferase, incorporating only 48 to $65 \%$ of that observed for three normal $\alpha_{2} \mathrm{M}$ preparations. Similar differences were observed when neuraminidase-treated $\alpha_{2} \mathrm{M}$ preparations were used as the acceptor substrate (not shown). Using either normal or CF enzyme source, the incorporation of sialic acid into neuraminidase-desialylated CF $\alpha_{2} \mathrm{M}$ was 54 to $68 \%$ of that found for neuraminidase-desialylated normal $\alpha_{2} \mathrm{M}$.

The activity of $\alpha$-N-acetylneuraminidase (Fig. 1, reaction 6) toward neuramine lactose and fetuin in cultured skin fibroblast of three CF patients and three normal controls is shown in Table 3. Wide range of activity was found for each cell type, but no significant differences were found between the two groups. The

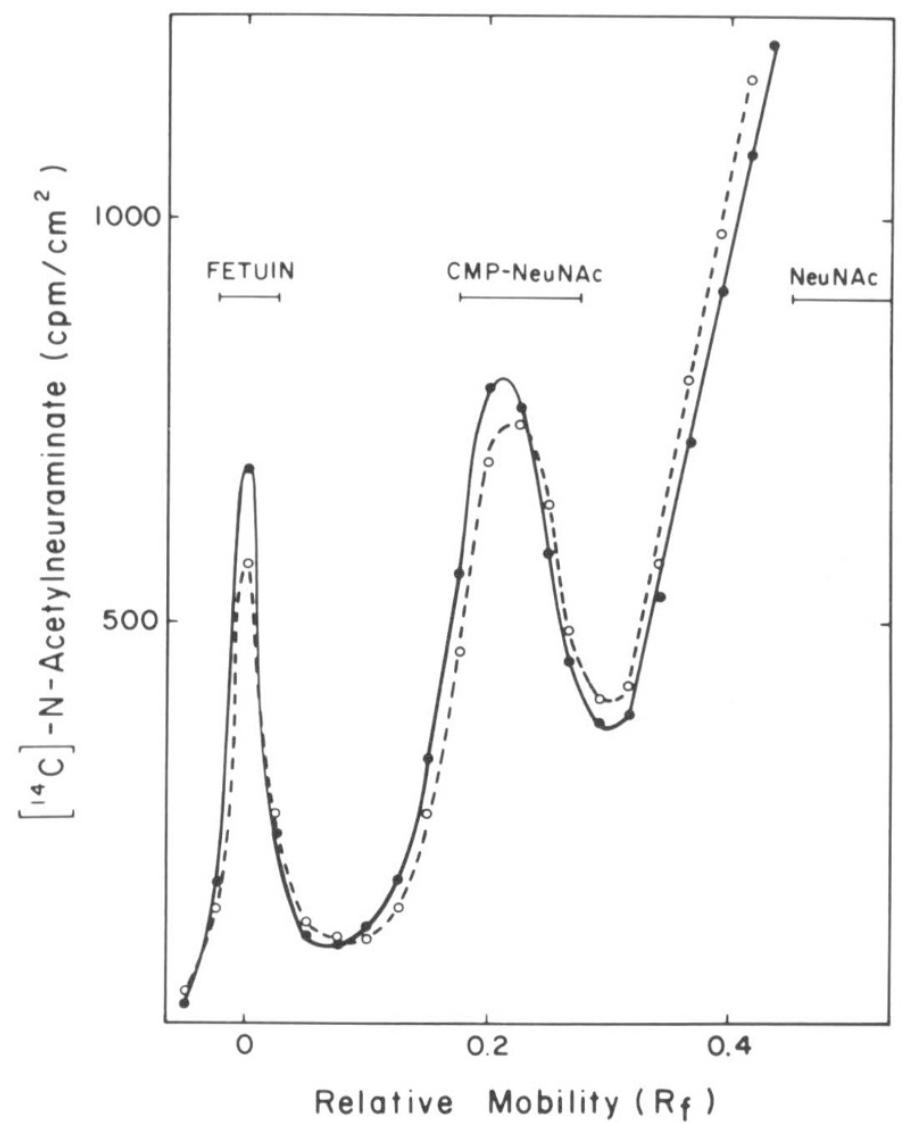

Fig. 2. Paper chromatography of the products of sialic acid activation and fetuin sialylation in homogenates of cultured skin fibroblasts from normal control $(-)$ and a patient with $\mathrm{CF}(\bigcirc)$. The reaction mixture contained $100 \mu \mathrm{g}$ cell lysate protein, $1 \mu$ mole $\left[4-{ }^{14} \mathrm{C}\right] N$-acetylneuraminic acid ( $10,800 \mathrm{dpm} / \mathrm{nmole}$ ), $1 \mu$ mole CTP, $0.2 \mathrm{mg}$ asialofetuin, and $4 \mu$ moles $\mathrm{MgCl}_{2}$ in $0.2 \mathrm{ml}$ of $0.1 \mathrm{M}$ Tris- $\mathrm{HCl}$ buffer, $\mathrm{pH} 8.2$. After $2 \mathrm{hr}$ incubation at $37^{\circ} \mathrm{C}$, the reaction mixture was chromatographed on Whatman No. 3 paper in $0.1 \mathrm{M}$ ammonium acetate buffer, $\mathrm{pH} 7.5$, containing $70 \%(\mathrm{v} / \mathrm{v})$ ethanol. The relative mobilities $\left(R_{f}\right.$ values) were 0 for fetuin, 0.22 for CMP-NeuNAc, and 0.61 for free sialic acid.
Table 2. Incorporation of sialic acid into exogenous asialoglycoproteins in plasma and fibroblasts

\begin{tabular}{|c|c|c|c|c|c|}
\hline \multirow{2}{*}{$\begin{array}{l}\text { Acceptor } \\
\text { substrate }\end{array}$} & \multirow[b]{2}{*}{ No. } & \multicolumn{2}{|c|}{ Plasma } & \multicolumn{2}{|c|}{ Fibroblasts } \\
\hline & & Normal (3) & CF (3) & Normal (3) & CF (3) \\
\hline None & & $84 \pm 6.7^{1}$ & $78 \pm 7.1$ & $153 \pm 13$ & $135 \pm 13$ \\
\hline Fetuin & & $1940 \pm 168$ & $1980 \pm 181$ & $2820 \pm 198$ & $2950 \pm 218$ \\
\hline Normal $\alpha_{2} \mathrm{M}$ & 3 & $476 \pm 34$ & $494 \pm 40$ & $800 \pm 67$ & $789 \pm 74$ \\
\hline $\mathrm{CF} \alpha_{2} \mathrm{M}$ & 3 & $270 \pm 28^{2}$ & $302 \pm 21^{2}$ & $575 \pm 62^{2}$ & $522 \pm 58^{2}$ \\
\hline
\end{tabular}

${ }^{1}$ Mean $\mathrm{cpm} / \mathrm{mg}$ glycoprotein \pm S.D.

${ }^{2} P<0.01$ as compared to normal $\alpha_{2} \mathrm{M}$.

Table 3. N-Acetylneuraminidase activity in cultured skin fibroblasts

Enzyme activity (nmoles/hr/mg protein)

\begin{tabular}{lcc} 
Cell line & $\begin{array}{c}\text { Neuramine } \\
\text { lactose }\end{array}$ & Fetuin \\
\hline $\begin{array}{c}\text { Normal controls } \\
1\end{array}$ & 19.8 & \\
2 & 30.0 & 2.92 \\
3 & 38.7 & 4.35 \\
CF & & 5.14 \\
1 & & \\
2 & 28.8 & 3.73 \\
3 & 45.0 & 5.85 \\
& 32.6 & 4.71 \\
\hline
\end{tabular}

ratio of the rate of hydrolysis of the low-molecular-weight substrate (neuramine lactose) to that of the high-molecular-weight substrate (fetuin) in the CF fibroblast lysates was similar to the ratio found for the corresponding activities of the normal controls. Neuraminidase activity of either CF or normal fibroblasts toward $\mathrm{CF}-\alpha_{2} \mathrm{M}$ preparations (three of each), $3.96 \pm 0.19$, did not differ significantly from the activity toward normal- $\alpha_{2} \mathrm{M}$ preparations, $3.35 \pm 0.62$.

\section{DISCUSSION}

The possible involvement of an abnormal sialic acid metabolism in cystic fibrosis has been indicated by many reports $(1,13)$ describing an altered carbohydrate moiety in CF glycoproteins. The altered binding of CF glycoproteins to lectins $(5,19)$ and especially to wheat germ agglutinin which was shown to interact specifically with $\mathrm{N}$-acetyl-neuraminic acid (15), provides an indirect evidence for an abnormal number or accessibility of sialic acid residues. The most consistent finding of altered carbohydrate composition in crude glycoprotein fractions from CF patients is a reduced ratio of sialic acid to L-fucose (1). Decreased content of sialic acid was also observed in purified glycoprotein preparations from CF patients as compared to that of normal controls $(2,5)$. In view of all these findings, we have undertaken the present study to compare the metabolism of sialic acid in $\mathrm{CF}$ patients and normal controls.

Glycoprotein sialic acid originates from two sources: (1) the synthesis de novo from $\mathrm{N}$-acetylmannosamine and phosphoenol pyruvic acid (ManNAc + ATP + PEP $+2 \mathrm{H}_{2} \mathrm{O} \rightarrow$ NeuNAc + adenosine 5 '-diphosphate +2 -phosphoric acid; (2) the recycling of sialic acid from sialic acid-containing glycoconjugates, by $\alpha-N$ acetyl-neuraminidases (glycoconjugates $\rightarrow$ asialo-glycoconjugates + NeuNAc). The synthesis of sialic acid represents the overall reaction of three enzymes: ManNAc kinase, NeuNAc-9-P synthase, and NeuNAc-9-P phosphatase. The normal rate of synthesis determined in fibroblasts from CF patients and the similar residual activity when ATP or PEP were excluded from the reaction mixture, indicate that neither of these enzymes is deficient in CF. Sialidase activity in CF, as determined using a glycoprotein (fetuin) or an oligosaccharide (neuramine lactose) substrate, was also within the range of activity of normal controls. 
The activation of the free sialic acid by formation of CMP-sialic acid is a prerequisite for the sialylation step in which sialic acid is transferred from the nucleotide sugar donor into a glycoprotein acceptor. The activity of CTP:sialic acid cytidylyltransferase in CF fibroblasts did not differ significantly from that of normal cells, and addition of asialofetuin into the reaction mixture resulted in similar pattern of incorporation for both cell types. In contrast to asialofetuin, the sialylation of desialylated preparations of purified $\alpha_{2} \mathrm{M}$ from CF plasma was poor and found to be 48 to $65 \%$ of that determined for desialylated preparations of normal $\alpha_{2} \mathrm{M}$. However, the reduced sialylation of CF $\alpha_{2} \mathrm{M}$ could not be attributed to a defective sialyltransferase because similar results were observed using plasma or fibroblast from either CF patients or normal controls, as the enzyme source. Both the CF and the normal enzyme possessed relatively high activity toward normal $\alpha_{2} \mathrm{M}$, whereas the CF $\alpha_{2} \mathrm{M}$ species was a poor glycoprotein substrate. The decreased content of sialic acid, previously found (5) for $\mathrm{CF} \alpha_{2} \mathrm{M}$, may account for the reduced sialylation of this glycoprotein species. An opposite pattern has been reported (11) for the fucosylation reaction in CF, namely, using fucosyltransferase from either CF or normal plasma, the incorporation of $\mathrm{L}$ fucose into a glycoprotein acceptor from CF saliva was significantly higher than the incorporation into the glycoprotein acceptor from control. The decreased sialylation and increased fucosylation of $\mathrm{CF}$ glycoproteins are in agreement with the previously reported (1) decreased ratio of sialic acid to $\mathrm{L}$-fucose in glycoprotein fractions from CF patients.

The enzymes involved in the metabolism of sialic acid in $\mathrm{CF}$ patients appear to be normal and could not account for the observed differences. The altered carbohydrate composition and the altered glycosylation reactions of CF glycoproteins are probably the result of a defect prior to the sialylation of the oligosaccharide portion. The metabolism of additional glycoprotein sugars should be examined to find out if a general defect in the glycosylation process might be involved in $\mathrm{CF}$.

\section{REFERENCES AND NOTES}

1. Alhadeff, J. A.: Glycoproteins and cystic fibrosis: A review. Clin. Genet., 14: 189 (1978).

2. Alhadeff, J. A.. Watkins, A. P. and Freeze, H.: Purification and characterization of altered cystic fibrosis liver $\alpha$-L-fucosidase. Clin. Genet., 13: 417 (1978).

3. Aminoff, D.: Methods for quantitative estimation of $N$-acetylneuraminic acid and their application to hydrolysates of sialomucoids. Biochem. J., 81: 384 (1961).

4. Ben-Yoseph, Y., Burton, B. K., and Nadler, H. L.: Quantitation of the enzymically deficient cross reacting material in $\mathrm{GM}_{1}$ gangliosidosis. Am. J. Hum. Genet., 29: 575 (1977).

5. Ben-Yoseph, Y., DeFranco, C. L., and Nadler, H. L.: Decreased sialic acid and altered binding to lectins of purified $\alpha_{2}$-macroglobulin from patients with cystic fibrosis. Clin. Chim. Acta, 99: 31 (1979).

6. Bradford, M. M.: A rapid and sensitive method for the quantitation of microgram quantities of protein utilizing the principle of protein-dye binding. Anal. Biochem., 72: 248 (1976).

7. Bray, G. A.: A simple efficient liquid scintillator for counting aqueos solutions in a liquid scintillation counter. Anal. Biochem., l: 279 (1960).

8. Comings, D. E., LeFever, L. A., Ben-Yoseph, Y., and Nadler, H. L.: Normal two-dimensional gel electrophoresis of $\alpha_{2}$-macroglobulin in cystic fibrosis. Am. J. Hum. Genet., 32: 273 (1980).

9. diSant'Agnese, P. A., and Davis, P. B.: Research in cystic fibrosis. N. Engl. J. Med., 295: 481 (1976).

10. Dische, Z., Pallavicini, J. C., Cizek, L. J., and Chien, S.: Changes in the control of secretion of mucus glycoproteins as possible pathogenic factor in cystic fibrosis of the pancreas. Ann. N. Y. Acad. Sci., 93: 526 (1962).

11. Guha, A. K., Kutty, K. M., Chandra, R. K., and Way, R. C.: A study of the salivary glycoprotein in cystic fibrosis patients and controls: fucose incorporation and protein pattern. Clin. Biochem., 10: 153 (1977).

12. Kean, E. L., and Roseman, S.: CMP-sialic acid synthetase (Cytidine-5'-monophospho-sialic acid synthetase). Methods Enzymol., 8: 208 (1966).

13. Nadler, H. L., Rao, G. J. S., and Taussig, L. M.: Cystic Fibrosis: In: J. B. Stanbury, J. B. Wyngaarden, D. S. Fredrickson: The Metabolic Basis of Inherited Disease. 4th Ed. pp. 1683-1710 (McGraw-Hill, New York. 1978).

14. Pallavicini, J. C., Gabriel, O., di Sant'Agnese, P. A., and Burkirk, E. R.: Isolation and characterization of carbohydrate-protein complexes from human sweat. Ann. N. Y. Acad. Sci., 106: 330 (1963).

15. Peters, B. P., Ebisu, S., Goldstein, I. J., and Flashner, M.: Interaction of wheatgerm agglutinin with sialic acid. Biochemistry, 18: 5505 (1979).

16. Roelfs, R. E.. Gibbs, G. E. and Griffin, G. D.: The composition of rectal mucus in cystic fibrosis. Am. J. Dis. Child., 113: 419 (1967).

17. Shapira, E., Ben-Yoseph, Y. and Nadler, H. L.: Decreased formation of $\alpha_{2}$ macroglobulin-protease complexes in plasma of patients with cystic fibrosis. Biochem. Biophys. Res. Commun., 71: 864 (1976).

18. Shapira, E., Martin, C. L., and Nadler, H. L.: Comparison between purified $\alpha_{2-}$ macroglobulin preparations from normal controls and patients with cystic fibrosis. J. Biol. Chem., 252: 7923 (1977).

19. Shapira, E., and Menendez, R.: Increased binding of concanavalin A to $\alpha_{2}$. macroglobulin, IgM and IgG from cystic fibrosis plasma. Biochem. Biophys. Res. Commun., 93: 50 (1980).

20. Warren, L., and Glick, M. C.: Enzymatic preparation of ${ }^{14} \mathrm{C}-\mathrm{N}$-acetylneuraminic acid. Methods Enzymol., 8: 131 (1966).

21. Appropriate informed consents were obtained for this study.

22. Two cultured skin fibroblast lines from patients with cystic fibrosis, GM 142 and GM 768, were obtained from the Human Genetic Mutant Cell Repository. Camden, NJ.

23. Data from this study were presented in part at the Thirtieth Annual Meeting of the American Society of Human Genetics, Minneapolis, MN, October 3-6. 1979.

24. Dr. H. L. Nadler is the Irene Heinz Given and John LaPorte Given Research Professor of Pediatrics.

25. The authors thank Drs. H. Wessel and J. Herman for helping us to obtain specimens from their patients.

26. Requests for reprints should be addressed to: Dr. Yoav Ben-Yoseph, 2300 Children's Plaza, Chicago, IL 60614 (USA)

27. This research was supported by grants from the National Institutes of Health RO1 AM 18642 and the National Foundation-March of Dimes.

28. Received for publication June 18, 1980.

29. Accepted for publication October 3, 1980. 